\begin{tabular}{|c|l|}
\hline Title & Molecular phy logeny of a red-snow-crab species complex using mitochondrial and nuclear DNA markers. \\
\hline Author(s) & $\begin{array}{l}\text { Azuma, Noriko; Grant, William S; Templin, William D; Kunihiro, Y asushi; Minara, Eiji; Y Ynagimoto, T akashi; A be, } \\
\text { Syuiti }\end{array}$ \\
\hline Citation & $\begin{array}{l}\text { Zoological science, 28(4), 286-292 } \\
\text { https://doi.org/L0.2108/2s. 28.286 }\end{array}$ \\
\hline Issue Date & 2011-04 \\
\hline Doc URL & http://hdl.handle.net/2115/54511 \\
\hline Type & article \\
\hline File Information & 7)zsj.28.286.pdf \\
\hline
\end{tabular}

Instructions for use 


\section{Molecular Phylogeny of a Red-Snow-Crab Species Complex using Mitochondrial and Nuclear DNA Markers}

Author(s): Noriko Azuma, William S. Grant, William D. Templin, Yasushi Kunihiro, Eiji Mihara, Takashi Yanagimoto and Syuiti Abe

Source: Zoological Science, 28(4):286-292. 2011.

Published By: Zoological Society of Japan

URL: http://www.bioone.org/doi/full/10.2108/zsj.28.286

BioOne (www.bioone.org) is an electronic aggregator of bioscience research content, and the online home to over 160 journals and books published by not-for-profit societies, associations, museums, institutions, and presses.

Your use of this PDF, the BioOne Web site, and all posted and associated content indicates your acceptance of BioOne's Terms of Use, available at www.bioone.org/page/terms_of_use.

Usage of BioOne content is strictly limited to personal, educational, and non-commercial use. Commercial inquiries or rights and permissions requests should be directed to the individual publisher as copyright holder. 


\title{
Molecular Phylogeny of a Red-snow-crab Species Complex Using Mitochondrial and Nuclear DNA Markers
}

\author{
Noriko Azuma1*, William S. Grant ${ }^{2,3}$, William D. Templin², Yasushi Kunihiro ${ }^{4}$, \\ Eiji Mihara ${ }^{5}$, Takashi Yanagimoto ${ }^{6}$ and Syuiti $\mathrm{Abe}^{7}$ \\ ${ }^{1}$ Nodai Bioresource Institute, Tokyo University of Agriculture, 196 Yasaka, Abashiri, Hokkaido 099-2493, Japan \\ ${ }^{2}$ Gene Conservation Laboratory, Alaska Department of Fish and Game, 333 Raspberry Road, \\ Anchorage, Alaska 99518, USA \\ ${ }^{3}$ Department of Biological Sciences, University of Alaska Anchorage, Anchorage, Alaska 88508, USA \\ ${ }^{4}$ Mariculture Fisheries Research Institute, Hokkaido Research Organization \\ Fisheries Research Department, 1-156-3 Funami-cho, \\ Muroran, Hokkaido 051-0013, Japan \\ ${ }^{5}$ Wakkanai Fisheries Research Institute, Hokkaido Research Organization \\ Fisheries Research Department, 4-5-15 Suehiro, \\ Wakkanai, Hokkaido 097-0001, Japan \\ ${ }^{6}$ National Research Institute of Far Seas, Fisheries Research Agency, 2-12-4 \\ Fukuura, Kanazawa-ku, Yokohama, Kanagawa 236-8648, Japan \\ ${ }^{7}$ Division of Marine Bioscience, Graduate School of Fisheries Sciences, \\ Hokkaido University, 3-1-1 Minato-cho, Hakodate, \\ Hokkaido 041-8611, Japan
}

\begin{abstract}
Nucleotide sequence variation of mitochondrial DNA COI and nuclear rRNA gene regions was used to reconstruct phylogenetic relationships for the red-snow-crab species complex, including the red snow crab, Chionoecetes japonicus, its nominal subspecies, $C$. japonicus pacificus, and the triangle tanner crab, $C$. angulatus. The topologies of the Bayesian and neighbor-joining (NJ) trees of the $\mathrm{COI}$ and of $\mathrm{NJ}$ trees of rRNA sequences placed $\mathrm{C}$. japonicus and $\mathrm{C}$. angulatus in a single clade. The net sequence divergence between these taxa was $d_{\text {net }}=0.000$ in COI, and strongly suggests that these taxa represent a single species. In contrast, haplotypes in $C$. $j$. pacificus clustered separately from the $C$. japonicus $-C$. angulatus clade. Net sequence divergence from $C$. japonicus $-C$. angulatus to $C$. $j$. pacificus was $d_{\text {net }}=0.026$ in $C O$, indicating that $C$. $j$. pacificus should be elevated to a separate species, C. pacificus. A $165 \mathrm{bp}$ insert appeared in the rRNA gene of $C$. $j$. pacificus, but was absent in the remaining species of Chionoecetes. This autapomorphic condition in $C$. $j$. pacificus adds support for an independent evolution of this taxon. Evolutionary divergences between these taxa may reflect contrasting evolutionary process influenced by ocean bathymetry.
\end{abstract}

Key words: molecular phylogeny, cytochrome oxidase subunit 1, speciation, rDNA, Decapoda

\section{INTRODUCTION}

Marine animals with planktonic larvae potentially disperse long distances in ocean-currents, and generally show little genetic population structure over the species' range (Palumbi, 1994). For example, populations of sea urchins in the genera Echinometra and Diadema tend to show little divergence from one another on regional scales along a coast. However, on ocean-wide scales, these genera are subdivided into several species (McCartney et al., 2000; Lessios et al., 2001). Most models invoke divergence and

\footnotetext{
${ }^{*}$ Corresponding author. Phone: $+81-152-48-3903$;

Fax : +81-152-48-3897;

E-mail: anoriko@fish.hokudai.ac.jp
}

Supplemental material for this article is available online. doi:10.2108/zsj.28.286 reproductive isolation in allopatry to account for marine speciation (e.g. Palumbi, 1994; Floeter et al., 2008; Rocha and Bowen, 2008). Populations can become geographically isolated for several reasons, including shoreline changes from tectonic movements, drops in sea level, and changes in current patterns that redirect larval dispersals (Palumbi, 1994).

Crabs in the genus Chionoecetes (Decapoda, Brachyura) are widely distributed in the cold-temperate and subpolar waters of the Northern Hemisphere. These crabs have large body sizes and relatively large populations, which support economically important fisheries in the USA, Canada, Russia, and Japan. The genus presently includes five species, divided into two groups based on vertical distribution. Shallow-water species on continental shelves include the Tanner crab, C. bairdi Rathbun, 1893, and snow crab, C. opilio Fabricius, 1788. Deep-water species on the continental slope include the red snow crab, C. japonicus 
Rathbun, 1932, triangle Tanner crab, C. angulatus Rathbun, 1893, and grooved Tanner crab, C. tanneri Rathbun, 1893 (Jadamec et al., 1999).

Populations of $C$. japonicus extend from the central Sea of Japan and along the Pacific coast of northern Japan to the Sea of Okhotsk. Adults occur at 500-3000 m depth, with the greatest abundances at about $1000 \mathrm{~m}$ (Yosho and Hayashi, 1994). Chionoecetes angulatus inhabits deep waters extending from the Sea of Okhotsk, across the Bering Sea, and into the Northeast Pacific as far as Oregon (Jadamec et al., 1999). Although the distributions of both species overlap in the Sea of Okhotsk, these species putatively can be distinguished by carapace morphology. The spine at the intersection of the two dorsal ridges on the carapace is large in $C$. angulatus, but small in $C$. japonicus (Jadamec et al., 1999). Spine length, however, appears to vary along a continuum within species, and no quantitative data are available on spine-length variability in these species. The validity of this morphological trait for classification has been questioned by Somerton and Donaldson (1996), because of similarities between the two species in vertical distribution, size at maturity, and body shape. The nominal subspecies $C$. japonicus pacificus occurs allopatrically on seamounts, e.g. the Emperor Seamounts, in the mid North Pacific and is discriminated from the typical red snow crab, C. japonicus japonicus, by carapace color (Sakai, 1978).

The present study aims to clarify the phylogenetic relationships among the three taxa in the red-snow-crab species complex, as well as to reconstruct a phylogeny using both nuclear and mitochondrial (mt) DNA markers for all the species in the genus Chionoecetes, including the three other North Pacific species: the grooved Tanner crab, C. tanneri, snow crab, C. opilio, and Tanner crab, C. bairdi. Chionoecetes tanneri is distributed from the CaliforniaMexico border in the Northeastern Pacific northward to the Bering Sea. The morphology of this species differs greatly from that of both the red snow and triangle Tanner crabs (Jadamec et al., 1999), indicating a distant relationship from the remaining three red-snow-crab taxa. C. opilio has the widest distribution, extending from the Sea of Japan, east of the Korean Peninsula, through the Sea of Okhotsk and the Bering Sea, and into the Northwest Atlantic. Chionoecetes bairdi occurs in the North Pacific from the southeastern Bering Sea to Oregon, and westward from the Aleutian Islands to Hokkaido, Japan.

A previous phylogenetic study using 5' region of nucleotide sequences of the cytochrome $c$ oxidase subunit 1 (COI) and 16S ribosomal rRNA genes of the mtDNA (Yanagimoto, 2007a) failed to resolve relationships among C. japonicus, C. opilio and C. bairdi, because of small sample sizes for each species and because of inconsistent results from the two mtDNA markers. The present study included larger sample sizes of $C$. japonicus, $C$. j. pacificus, C. opilio and C. tanneri, but only a small sample of $C$. bairdi, to examine phylogenetic relationships among species. The $3^{\prime}$ region of nucleotide sequence in the COI gene resolved the population structure of the hair crab Erimacrus isenbeckii around Japan (Azuma et al., 2008), and was used here to infer relationships among the taxa of Chionoecetes. A molecular-clock calibration was used to date the nodes in the phylogenetic tree for Chionoecetes. The struc- tural variation of internal spacer regions in a nuclear rRNA gene also was examined, because this variability has been informative for phylogenetic inferences in other crab taxa (Tang et al., 2003; Yanagimoto, 2007b).

\section{MATERIALS AND METHODS}

\section{Sample collection and DNA extraction}

In this study, the name $C$. japonicus refers to Chionoecetes japonicus japonicus, but excludes Chionoecetes japonicus pacificus. Individuals of $C$. japonicus $(n=421)$ were collected from nine localities in the Sea of Japan, the Sea of Okhotsk, and the northwestern Pacific Ocean (Table 1, Fig. 1). Individuals of $C$. $j$. pacificus $(n=48$ ) were collected from the Emperor Seamount in the mid-Pacific, and individuals of $C$. angulatus $(n=95)$ were collected from the southeastern Bering Sea. Two samples of $C$. tanneri were collected in the eastern Bering Sea and the Gulf of Alaska $(n=96)$, and samples of $C$. opilio $(n=78)$ and $C$. bairdi $(n=5)$ were collected in the northwestern Pacific off Hokkaido, Japan.

Genomic DNA was extracted from about $20 \mathrm{mg}$ of leg muscle of adults with a PUREGENE ${ }^{T M}$ kit (Qiagen) or DNeasy ${ }^{T M}$ Blood \& Tissue kit (Qiagen), following the manufacturer's protocols. Extracted DNA was dissolved in 150-250 $\mu \mathrm{L}$ Tris-EDTA, $\mathrm{pH}$ 8.0.

\section{Mitochondrial DNA analysis}

About $600 \mathrm{bp}$ of the $3^{\prime}$ end of the $\mathrm{COI}$ gene was amplified with the polymerase chain reaction (PCR) using the brachyuran specific primers KBCOImf (5'-ATTGTTAGTCAAGAATCCGG-3', Azuma et al., 2008) and BeCOIr1 (5'-GGTAAATAATACAGAGCG-3', newly designed for the present study). The PCR solution including $100 \mu \mathrm{M}$ of each dNTP, $0.3 \mu \mathrm{M}$ of each primer, $0.5 \mathrm{U}$ of Taq DNA polymerase (Sigma) and $10 \mathrm{x}$ buffer was prepared following manufacturer's protocols, and 5-15 ng of genomic DNA was added to each $20 \mu \mathrm{l}$ solution as template. Thermal-cycle profiles consisted of an initial denaturation at $94^{\circ} \mathrm{C}$ for $3 \mathrm{~min}$, followed by 35 cycles of $95^{\circ} \mathrm{C}$ for $45 \mathrm{~s}, 48^{\circ} \mathrm{C}$ for $30 \mathrm{~s}$ and $72^{\circ} \mathrm{C}$ for $60 \mathrm{~s}$, with a post-cycle extension at $72^{\circ} \mathrm{C}$ for $5 \mathrm{~min}$. PCR products were purified with magnetic beads (AMPure, Agencourt, Bervery, MA) and sequenced on a 3130xl genetic analyzer (Applied Biosystems) with the BigDye Terminator Sequencing Ready Reaction 3.1 (Applied Biosystems) using the forward and reverse primers noted above. Sequences were aligned and edited to $550 \mathrm{bp}$ with DNASIS (Hitachi) and deposited in DDBJ (Accession nos. AB450389-AB450427, $A B 450658-A B 450688, \quad A B 451006-A B 451017, \quad A B 469203-$

Table 1. Samples of Chionoecetes crabs used in this study. $N$ is sample size, and year, latitude and longitude indicate the date and place of collection samples. * purchased in market as crabs from the Sea of Okhotsk.

\begin{tabular}{lrrcc}
\hline Taxon & N & Year & Latitude & Longitude \\
\hline Chionoecetes japonicus & 53 & 2006 & $46.4 \mathrm{~N}$ & $146.0 \mathrm{E}$ \\
& 55 & 2005 & \multicolumn{2}{c}{ no data* $^{*}$} \\
& 48 & 2005 & $45.9 \mathrm{~N}$ & $140.1 \mathrm{E}$ \\
& 49 & 2006 & $45.8 \mathrm{~N}$ & $139.8 \mathrm{E}$ \\
& 36 & 2005 & $42.4 \mathrm{~N}$ & $139.5 \mathrm{E}$ \\
& 44 & 2005 & $41.4 \mathrm{~N}$ & $140.0 \mathrm{E}$ \\
& 56 & 2008 & $36.4 \mathrm{~N}$ & $134.3 \mathrm{E}$ \\
& 35 & 2005 & $42.3-42.4 \mathrm{~N}$ & $144.0-144.3 \mathrm{E}$ \\
& 45 & 2007 & $37.1 \mathrm{~N}$ & $134.3 \mathrm{E}$ \\
C.japonicus pacificus & 48 & 2007 & $41.1 \mathrm{~N}$ & $170.4 \mathrm{E}$ \\
C.angulatus & 95 & 1996 & $54.8 \mathrm{~N}$ & $167.5 \mathrm{~W}$ \\
C.tanneri & 48 & 1994 & $56.3 \mathrm{~N}$ & $170.4 \mathrm{~W}$ \\
& 48 & 1996 & $54.0 \mathrm{~N}$ & $162.0 \mathrm{~W}$ \\
C.bairdi & 5 & 2005 & $42.5 \mathrm{~N}$ & $144.0 \mathrm{E}$ \\
C.opilio & 78 & 2005 & $42.5 \mathrm{~N}$ & $144.0 \mathrm{E}$ \\
\hline
\end{tabular}




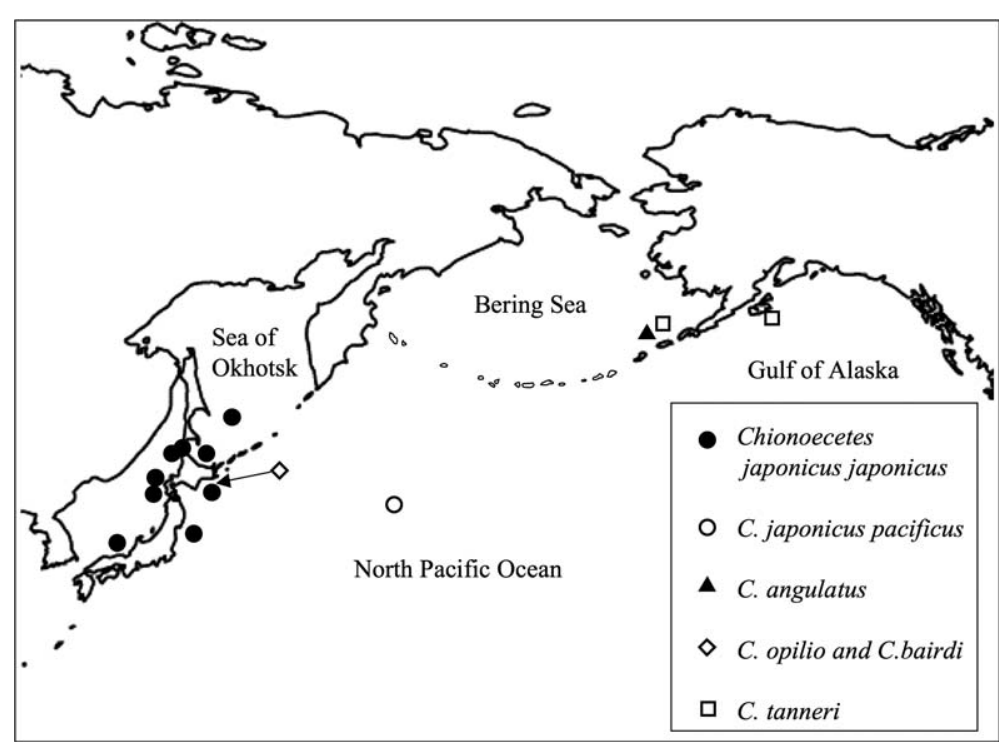

Fig. 1. Map of the North Pacific and NW Pacific showing sample collection sites of Chionoecetes japonicus around Japan, $C$. angulatus in the southeastern Bering Sea and $C$. japonicus pacificus in the mid Pacific Ocean.

\section{AB469282).}

The Akaike information criterion (AIC) in MODELTEST 3.7 (Posada and Crandall, 1998) indicated that the sequences fit the Tamura-Nei substitution model (TrN; Tamura and Nei, 1993) with heterogeneous sites $\operatorname{TrN}+\mathrm{G}$ model (shape parameter $\alpha=0.596$ ). A neighbor-joining ( $\mathrm{NJ}$ ) tree was constructed using MEGA 4.0 (Tamura et al., 2007) with the appropriate substitution model with 10,000 bootstrap replicates to assess the significance of the nodes in the tree. A Bayesian tree was constructed with BEAST 1.5 (Drummond and Rambaut, 2007) and the TrN + G substitution model and visualized with FIGTREE 1.2.2 (Rambaut, http:// tree.bio.ed.ac.uk). Only representative divergent haplotypes from each taxon were used for Bayesian tree construction to shorten run times. For both the $\mathrm{NJ}$ and Bayesian trees, E. isenbeckii was used as an outgroup. The nodes in the Bayesian tree were dated using a molecular-clock calibration based on $2 \%$ sequence divergence per million years (Marko, 2002).

\section{Nucleotide sequence analysis of nuclear rRNA gene region}

A partial sequence (ca.1600 bp) of the nuclear rRNA gene region, including the ITS1, 5.8S rRNA gene and ITS2, was amplified for four individuals in each taxon with PCR using the primers 1828Sr-f (5'-AAAAAGCTTCCGTAGGTGAACCTGCG-3') and 1828Sr-r (5'-ATATGCTTAAATTCAGCGGG-3') (Sajdak and Phillips, 1997). Some individuals could not be well amplified, so we used a newly designed internal primer (crab28sR700) 5'-CGTCGGGCTGTGCCGACT-3', which is located ca. 25 bp upstream of $18-28 \mathrm{Sr}$ r. Reaction solution was prepared in the same manner for $\mathrm{COI}$ amplifications except the volume of genomic DNA was 50-100 ng. PCR cycles included an initial denaturation at $94^{\circ} \mathrm{C}$ for $3 \mathrm{~min}$, followed by 35 cycles of $95^{\circ} \mathrm{C}$ for $45 \mathrm{~s}, 55^{\circ} \mathrm{C}$ for $45 \mathrm{~s}$ and $72^{\circ} \mathrm{C}$ for 2 min, with a post-cycling extension at $72^{\circ} \mathrm{C}$ for $10 \mathrm{~min}$. PCR products were purified as for $\mathrm{COI}$ amplifications, and direct sequencing was carried out with the primers noted above on a $3130 \mathrm{xl}$ genetic analyzer (Applied Biosystems). Unique sequences were deposited in the GenBank/DDBJ Database. Sequences were aligned by eye using the software of DNASIS (Hitachi).

Both nucleotide substitutions and long insertions or deletions (indels) can occur among species in the sequences of the ITS region. A $165 \mathrm{bp}$ insertion occurred in C. j. pacificus, and we tested whether this indel was taxon-specific or represented within-species variability by surveying a length polymorphism of PCR products. Based on conserved sequence regions near the insertion in all examined taxa, new $P C R$ primers, insF1 (5'-GCAGTAGACTGTTGCGACAGAC-3') and insR1 (5'-CCAACCAAGCTCCCGGATGCTC-3'), were developed to detect the insertion. PCR was carried out using the insF1 and insR1 and genomic DNA from all individuals of $C$. j. pacificus, four each of $C$. japonicus and $C$. angulatus, and one each of C. opilio, C. tanneri and $C$. bairdi. Reaction components were basically similar to PCR for 18-28S rRNA except the primers. PCR cycles included an initial denaturation at $94^{\circ} \mathrm{C}$ for $3 \mathrm{~min}$, followed by 35 cycles of $95^{\circ} \mathrm{C}, 60^{\circ} \mathrm{C}$ and $72^{\circ} \mathrm{C}$ (each for $30 \mathrm{~s}$ ), and a post-cycling extension at $72^{\circ} \mathrm{C}$ for $10 \mathrm{~min}$. Electrophoresis in a $2.0 \%$ agarose gel in TAE was used to survey for the $165 \mathrm{bp}$ length polymorphism in the specimens.

Although species-specific indels may be phylogenetically informative, the occurrences of nested multiplesite polymorphisms make it difficult to assign weights to the indels in the construction of a phylogenetic tree. Therefore, only nucleotide substitutions in the ITS region were used to reconstruct a phylogenetic tree. An NJ tree of uncorrected $p$-distances between haplotypes was constructed with and without substitutions within the sites of indels (gap) using the software Clustal $X$ (Thompson et al., 2007). No outgroups were used, because of the complex structure of the ITS region in the species of Chionoecetes described above, which will not allow precise sequence alignment including distant species.

\section{RESULTS}

\section{Mitochondrial DNA analysis}

Nucleotide polymorphisms in the $550 \mathrm{bp} \mathrm{COI} \mathrm{sequences}$ from nine samples of $C$. japonicus from the Sea of Japan, the sea of Okhotsk and the Pacific Ocean $(n=421)$ defined 38 haplotypes. Seventeen haplotypes occurred in the sample of $C$. angulatus from the southeastern Bering Sea $(n=$ 95), of which 11 were shared with $C$. japonicus. Five private haplotypes occurred in $C$. angulatus as singletons, and one haplotype was found in two individuals. In the pooled sample of $C$. japonicus - C. angulatus $(n=516), 41$ polymorphic sites defined 44 haplotypes. A total of 36 polymorphic sites defined 29 haplotypes in the samples of $C$. $j$. pacificus $(n=48)$. Forty-six haplotypes occurred in $C$. tanneri $(n=96), 11$ in C. opilio $(n=50)$ and two in $C$. bairdi $(n=5)$. No indels were observed in these haplotypes within or among the latter three species.

Mean sequence divergences between haplotypes within species ranged from 0.0036 (C. angulatus) to 0.0099 (C. $j$. pacificus). Both the $\mathrm{NJ}$ and Bayesian trees placed the three taxa of the red-snow-crab complex into a monophyletic group with significant bootstrap support $(72 \%)$, but relatively weak posterior probability (0.47) (Figs. 2 and 3). Haplotypes of $C$. angulatus were interspersed among those of $C$. japonicus in the trees, and the two taxa shared an abundant haplotype (AB450423) with a frequency of 0.79 in $C$. japonicus and 0.83 in $C$. angulatus. Net sequence divergence between $C$. japonicus and $C$. angulatus was $d_{\text {net }}=$ 0.000 . Net sequence divergence between $C$. japonicus $-C$. angulatus and $C$. j. pacificus was $d_{\text {net }}=0.026$ (Table 2). The remaining three species were sister taxa to the red-snow- 
crab complex, showing different topologies between the Bayesian and NJ trees. The NJ tree placed C. bairdi outside all other species of Chionoecetes, while the Bayesian tree placed $C$. bairdi as a sister taxon to $C$. tanneri (posterior probability $=0.63$ ) (Figs. 2 and 3).

A molecular clock calibration of $2 \%$ divergence per million years indicated a separation between the red-snow-crab species complex and the remaining three species of Chionoecetes of about 4.6 million years ago (mya). However, the posterior probability and bootstrap value of this node was only 0.47 and $72 \%$, indicating the node is not supported by high probability. The node separating $C$. japonicus $-C$. angulatus and $C$. j. pacificus was suggested to be about 3.4 mya. The root of the $C$. japonicus and C. j. pacificus haplotypes was dated to about 2.1 mya and 2.3 mya, respectively, near the end of the Pliocene.

\section{rRNA gene sequence variability}

PCR for the rRNA region was not successful in some individuals, probably due to sequence polymorphisms in the priming sites. We obtained PCR products from four individuals in each of $C$. japonicus, C. angulatus, C. j. pacificus, $C$. tanneri and $C$. opilio and two in $C$. bairdi, and sequenced in three of $C$. japonicus, one each of $C$. angulatus and $C$. $j$. pacificus, two each of $C$. tanneri and $C$. opilio, but none of C. bairdi. The heterozygous rRNA gene region, i.e. occurrence of different haplotypes within individuals, probably caused the failure of sequencing in some PCR products even after successful amplification. Sequences from $C$. japonicus and one from $C$. angulatus were identical to the haplotype CJ1 of $C$. japonicus retrieved from GenBank (accession number: AB193504). Sequence of C. opilio matched the nucleotide sites 133-1531 of the GenBank haplotype $\mathrm{CO} 2$ (AB193500). Novel sequences of $C$. $j$. pacificus and $C$. tanneri were found in the present study and deposited in the DDBJ/Genbank with accession numbers AB5021212 and AB546598.

Additional sequences of the same region were retrieved from the GenBank for C. japonicus (hapolotypes CJ2 and CJ3; AB193505 and AB193506), C. opilio (CO1; $A B 193499)$, and C. bairdi (CB1 and CB2; AB193501 and $A B 193502)$. A total of nine sequences, each spanning 1593 bp with indels, were aligned, in which 329 polymorphic sites were found, including 278 indels and 62 nucleotide substitutions (Fig. 4 and Supplemental Table S1 online). Eleven single nucleotide polymorphisms occurred in the indels. The transversion/transition ratio was 0.931 , indicating almost equal frequency of the two types of substitutions. The longest indel was $165 \mathrm{bp}$ in the aforementioned ITS1 region of

Table 2. Net sequence divergence ( $\operatorname{TrN}$ ) between species of Chionoecetes based on 3 '-end sequences of the mtDNA COI gene.

\begin{tabular}{lccccc}
\hline \multicolumn{1}{l}{ 1. } & 2. & 3. & 4. & 5. \\
\hline 1. Chionoecetes japonicus & & & & & \\
2. C.angulatus & 0.0000 & & & & \\
3. C. japonicus pacificus & 0.0203 & 0.0319 & & & \\
4. C.tanneri & 0.0534 & 0.0534 & 0.0349 & & \\
5. C.bairdi & 0.0628 & 0.0630 & 0.0570 & 0.0517 & \\
6. C. opilio & 0.0600 & 0.0597 & 0.0432 & 0.0548 & 0.0660 \\
\hline
\end{tabular}

C. j. pacificus.

A schematic presentation of the characteristic sequences from each taxon is given in Fig. 4A. A homologous sequence of the longest insert occurred in the ITS2 region of all the examined taxa, including C. j. pacificus. The second longest insert of $67 \mathrm{bp}$ occurred in Chionoecetes

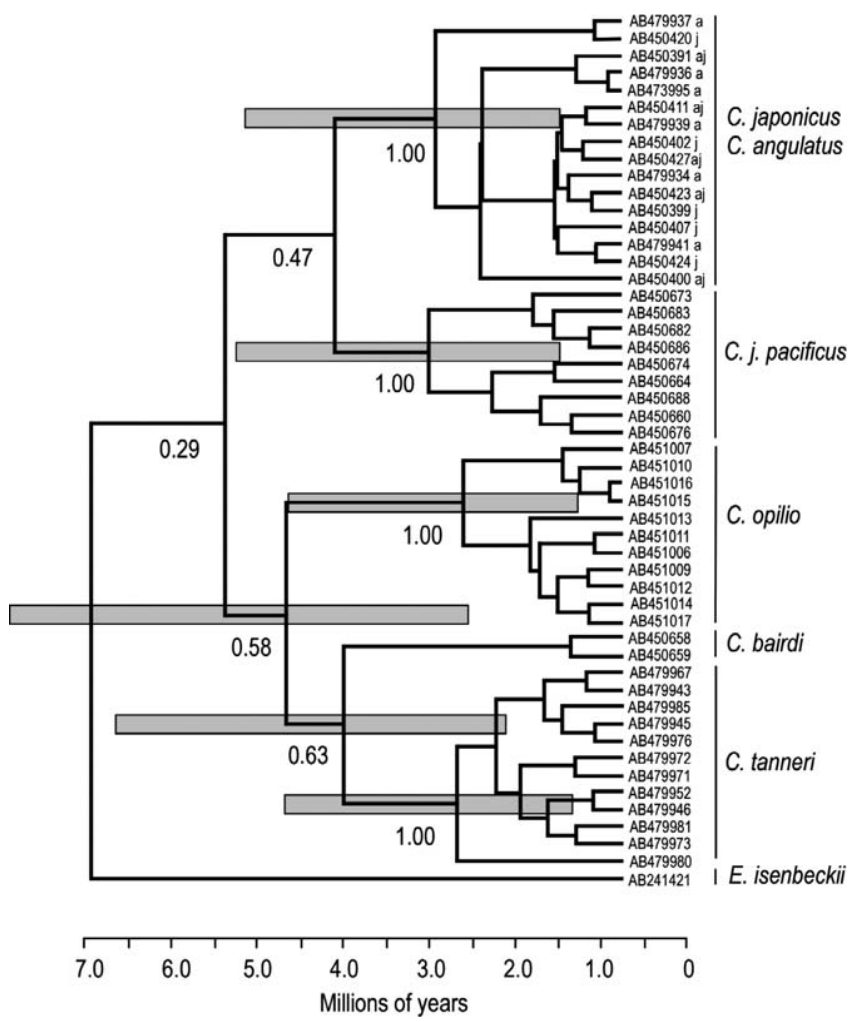

Fig. 2. Bayesian tree of $3^{\prime}$ region of $\mathrm{COI}$ based on Tamura-Nei distance showing relationships among Chionoecetes crab haplotypes. A common haplotype in Erimacrus isenbeckii was used as an outgroup. Bayesian posterior probabilities are shown at the nodes, and $95 \%$ highest probability densities for positions of nodes are indicated by gray bars. The letters 'a' and 'j', placed after GenBank accession numbers in the $C$. japonicus $-C$. angulatus cluster, indicate haplotypes appearing in samples of $C$. japonicus and $C$. angulatus.

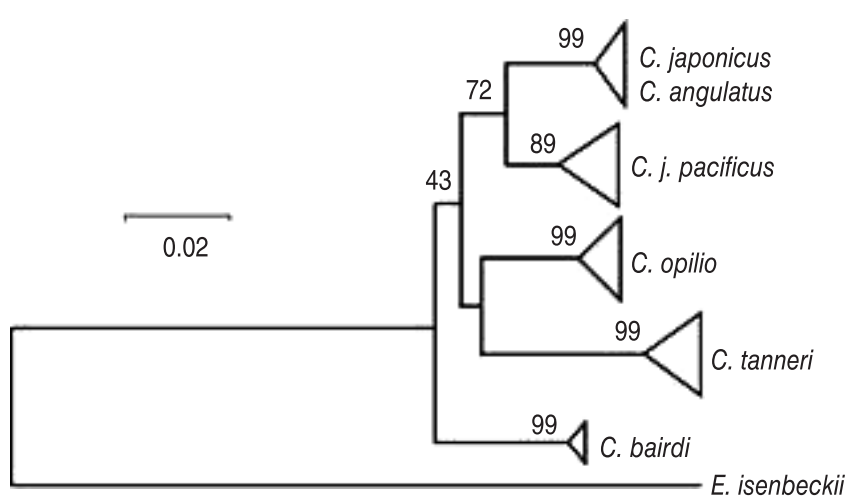

Fig. 3. Neighbor-joining tree of the $3^{\prime}$ region sequences of $\mathrm{COI}$ based on Tamura-Nei distance. Numbers at nodes represent bootstrap support with 10000 bootstrap replicates. The scale bar indicates sequence divergence. 
A

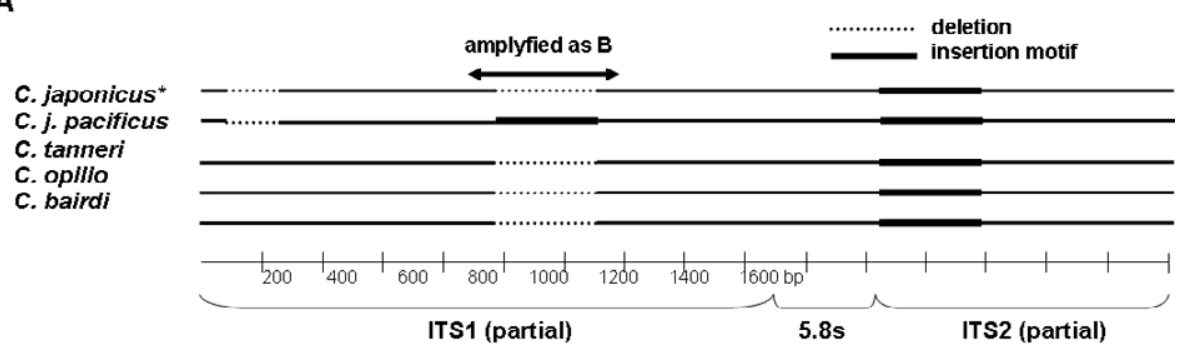

B

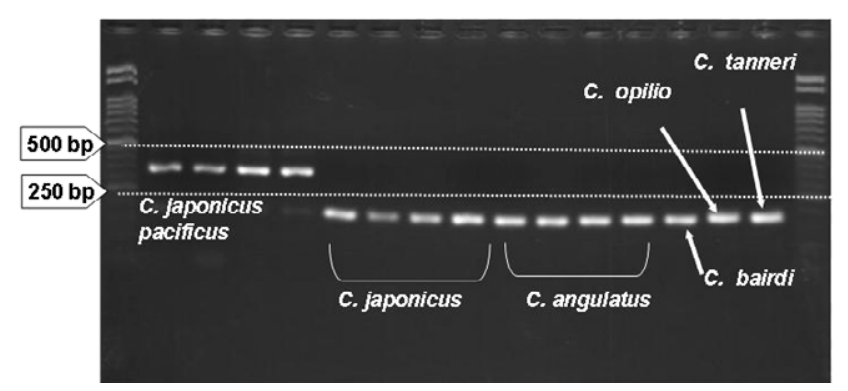

Fig. 4. (A) Structure of rRNA region examined in the present study. The horizontal line indicates a haplotype. *Sequence in $C$. angulatus was completely identical to one in C. japonicus. A 165 bp insert in ITS1 occurred only in C. japonicus pacificus. (B) Electrophoretic separation of PCR amplifications was carried out in $2.0 \%$ agarose gel in TAE buffer. PCR fragments were ca. 350 bp in C. j. pacificus, but ca. $180 \mathrm{bp}$ in the other species examined. plex, rather than an insertion in the other taxa, supporting the monophyly of the red-snow-crab species complex. The sequence in $C$. $j$. pacificus differed from the haplotype CJ1 by 11 substitutions and a 166 bp insert.

PCR amplification of the neighboring region of the longest insertion using insF1 and insR1 was successful in all examined specimens. Fig. 4B shows the electrophoretic separation of the PCR products. A comparison of the sequences indicated that the lengths of the PCR products were expected to be ca. $349 \mathrm{bp}, 177$ or $176 \mathrm{bp}, 182 \mathrm{bp}, 183 \mathrm{bp}$ and $182 \mathrm{bp}$ for $C$. j. pacificus, C. japonicus - C. angulatus, C. tanneri, C. opilio, and C. bairdi, respectively. The obtained PCR products of $C$. $j$. pacificus were distinguishable from those of other species on the electrophoretic gel, although such discrimination was not possible among C. japonicus - C. angulatus, $C$. tanneri, C. opilio, and C. bairdi. The longer PCR product of $C$. j. pacificus than that of the other taxa indicated the presence of the $165 \mathrm{bp}$ insert, which was absent in the others, including $C$. japonicus and $C$. angulatus. PCR products from all individuals of $C$. j. pacificus were about $350 \mathrm{bp}$ in length, indicating that the long insert in C. $j$. pacificus did not appear to reflect intra-specific variation but was specific to this taxon. Thus, the $165 \mathrm{bp}$ insert in the ITS1 region provides a discriminative marker for $C$. j. pacificus.

The NJ trees of ca. 1600 bp of partial rRNA sequence in Chionoecetes crabs based on $p$-distance with and without the nucleotide substitutions in the gapped sites supported the monophyly of $C$. japonicus, $C$. angulatus and $C$. $j$. pacificus, and significant bootstrap support suggested differentiation between C. japonicus and C. j. pacificus (Fig. 5). Additionally, C. japonicus - C. angulatus, C. j. pacificus and $C$. opilio were grouped together, but this group was not supported with a significant bootstrap value in the trees. The position of $C$. bairdi differed between the two trees. This species clustered with $C$. tanneri in the tree made without indels but was most divergent from the other taxa in the tree including indels. C. bairdi differed from the other taxa of Chionoecetes by species-specific substitution at 18 sites. However, seven of these substitutions were at positions 49, $50,51,59,79,98$, and 103, where some taxa had deletions (see Supplemental Table S1 online). Therefore, the seven substitutions were neglected in the analysis excluding indels, which led to different topologies in the trees constructed with and without indels.

\section{DISCUSSION}

The present study of mtDNA COI and nuclear rRNA gene sequence variation among species of Chionoecetes species other than $C$. japonicus - $C$. angulatus and $C$. $j$. pacificus. The $67 \mathrm{bp}$ region was considered to be a deletion in an ancestral lineage of the red-snow-crab species com- 
showed a close relationship between $C$. japonicus and $C$. angulatus, but a substantial amount of divergence between C. j. pacificus and the former two taxa. The molecular phylogenetic results of this study indicate that the taxonomies of the red-snow crab species complex should be revised.

\section{Taxonomies of $C$. japonicus and $C$. angulatus}

The results of the $\mathrm{COI}$ sequence analysis indicated a lack of species-level, or even subspecies-level divergence between the red snow crab $C$. japonicus and triangle tanner crab C. angulatus. First, the two taxa shared a common abundant haplotype. Second, haplotypes of these taxa were interspersed in the $\mathrm{NJ}$ tree based on the full population dataset (not shown) and the Bayesian tree with a reduced number of haplotypes (Fig. 2). Third, both the NJ (99\%) and Bayesian (100\%) trees provided a large amount of statistical support for the monophyly of haplotypes in the two taxa (Figs. 2 and 3). These results strongly suggest that $C$. japonicus and $C$. angulatus represent a single species and that these taxa should be synonymized.

One limitation of this conclusion is that only a single sample $(n=95)$ of $C$. angulatus from one location was included in the study. This sample was collected in the SE Bering Sea at the putative center of the distribution of $C$. angulatus and was separated by several thousand kilometers from the closest sample of $C$. japonicus used in this study. The large geographical distance from the nearest populations of $C$. japonicus makes it unlikely that the genetic similarity between these taxa was due to contemporary introgression or hybridization. Additional sequences in GenBank of $C$. angulatus from British Columbia, Canada extend the geographical scope of this conclusion. Sequence divergences between $\mathrm{COI}$ sequences at the $5^{\prime}$ end of the gene (597 bp; accession numbers AB211160 and AB211161 for C. japonicus, and $\mathrm{DQ} 882045$ for $C$. angulatus) were small. Net divergences were $d_{\text {net }}=0.0018$ between the two sequences of $C$. japonicus and $d_{\text {net }}=0.0060$ between these two sequences and one of $C$. angulatus from British Columbia. These small sequence divergences imply that there is little genetic differentiation among populations of $C$. angulatus, further supporting the synonomy of $C$. japonicus and $C$. angulatus.

The lack of nuclear rRNA sequence divergence between $C$. japonicus and $C$. angulatus also supports the synonomy of these taxa. An rRNA sequence in $C$. japonicus was identical to a homologous rRNA sequence in $C$. angulatus over a region spanning more than $1 \mathrm{kbp}$ (Fig. $4 \mathrm{~A})$. The $\mathrm{NJ}$ trees constructed from rRNA sequences with only nucleotide substitutions, but without indels, showed an identity of $C$. japonicus and $C$. angulatus and separation between $C$. japonicus and $C$. japonicus pacificus (Fig. 5). Thus both sequence datasets indicate a lack of divergence between $C$. japonicus and $C$. angulatus.

\section{Divergence of $C$. $j$. pacificus from $C$. japonicus $-C$. angulatus}

The trees based on $\mathrm{COI}$ sequences indicated a substantial degree of divergence between the red snow crab and the nominal subspecies, C. j. pacificus. Phylogenetic reconstructions suggest that the $C O I$ haplotypes of $C$. $j$. pacificus are monophyletic with a Bayesian probability of
$100 \%$ (Fig. 2). The net sequence divergence between $C$. japonicus $-C$. angulatus and $C$. j. pacificus was substantial $(d=0.026)$, and is typical of divergences between welldifferentiated species (Johns and Avise, 1998). The rRNA sequences also indicated a substantial amount of divergence between $C$. japonicus - $C$. angulatus and $C$. $j$. pacificus. The NJ trees constructed from substitutions showed a large amount of differentiation between $C$. japonicus and C. j. pacificus (Fig. 5). In addition, the $165 \mathrm{bp}$ insert in the rRNA ITS1 region of $C$. j. pacificus was absent, not only in red snow crabs, but also in the other three species of Chionoecetes. From the viewpoint of parsimonious evolution, this insertion should be considered to have occurred once, in only one lineage of $C$. j. pacificus among Chionoecetes taxa, suggesting that this species is independent from the other Chionoecetes. These results also support the elevation of C. j. pacificus to full species status.

\section{Molecular clock estimation and speciation scenario}

Sequence divergences of the $\mathrm{COI}$ between the $C$. japonicus $-C$. angulatus and $C$. j. pacificus and their geographical distributions give some insight into the timing and origin of the latter. Unlike most seamount clusters, one end of the Emperor Seamounts lies close to the continental shelf, so that dispersal from continental slope populations might have easily occurred given the duration of the planktonic larval stage and the obvious ability of continental slope populations to disperse across the rim of the North Pacific during warm interglacial periods. The Bayesian tree indicated a divergence between $C$. japonicus and $C$. j. pacificus about 3.4 mya. This estimate is close to the onset of a northern hemisphere ice age, when strong ocean-climate shift in temperature influenced the rim of the North Pacific. These temperature changes may have forced populations of the red snow crab to move south along the edge of Asian continental shelf and ancestral populations of $C$. $j$. pacificus may have migrated farther down the seamount chain, thereby isolating the two groups and promoting independent paths of adaptive divergence. Even though populations of these taxa may have been relatively close to one another during brief interglacial periods, they have been well isolated from each other by inhospitable conditions in the northern hemisphere most of the Pleistocene.

Northern cold-waters experienced considerable temperature fluctuations during the Quaternary, in addition to largescale shoreline changes (Takahashi, 1998). In the case of $C$. japonicus $-C$. angulatus, these fluctuations might have led to severe range contraction, followed by recovery and range expansion around the rim of the North Pacific, thereby resulting in wide distribution of this taxon. They may have expanded rapidly on the continuous continental slope which is highly suitable habitat. On the other hand, the geographical discontinuity between continental slope area and mid-ocean seamounts may have led to the isolation and speciation of C. j. pacificus.

\section{CONCLUSION}

Our analyses strongly suggested that $C$. japonicus and C. angulatus are a single species and their nomenclature should be synonymized, and that $C$. j. pacificus is an evolutionarily independent species that should be given full spe- 
cies recognition as $C$. pacificus. We used the rRNA gene region, which includes insertion/deletion of nucleotides, for species identification and phylogenetic inference. The present study is part of a series of studies in our laboratory on the population genetics of the red snow crab-triangle tanner crab complex. Additional studies of population structure can benefit from the use of high-resolution markers, such as microsatellite DNA.

\section{ACKNOWLEDGMENTS}

We thank W. Cheng, Alaska Department of Fish and Game, Anchorage, Alaska, Hokkaido Fisheries Experiment Station, and Daitokumaru Corporation, for providing samples. The Alaska Department of Fish and Game supported, in part, collaboration with N. Azuma. M. Grant provided helpful comments on the manuscript. This work was mainly supported by the 21 st COE Program (K-2) of Marine Bio-Manipulation Frontier for Food Production at Hokkaido University sponsored by the Ministry of Education, Culture, Sports, Science and Technology, Japan.

\section{REFERENCES}

Azuma N, Kunihiro Y, Sasaki J, Mihara E, Mihara Y, Yasunaga T, Jin D-H, Abe S (2008) Genetic variation and population structure of hair crab (Erimacrus isenbeckii) in Japan inferred from mitochondrial DNA sequence analysis. Mar Biotech 10: 39-48

Drummond AJ, Rambaut A (2007) BEAST: Bayesian evolutionary analysis by sampling trees. BMC Evol Biol 7: 214

Floeter SR, Rocha LA, Robertson DR, Joyeux JC, Smith-Vaniz WF, et al. (2008) Atlantic reef fish biogeography and evolution. J Biogeogr 35: 22-47

Jadamec LS, Donaldson WE, Cullenberg P (1999) Biological field techniques for Chionoecetes crabs. University of Alaska Sea Grant, AK-SG-99-02, Fairbanks

Johns GC, Avise JC (1998) A comparative summary of genetic distances in the vertebrates from the mitochondrial cytochrome $b$ gene. Mol Biol Evol 15: 1481-1490

Lessios HA, Kessing BD, Pearse JS (2001) Population structure and speciation in the tropical seas: global phylogeography of the sea urchin Diadema. Evolution 55: 955-975

Marko PB (2002) Fossil calibration of molecular clocks and the divergence times of geminate species pairs separated by the Isthmus of Panama. Mol Biol Evol 19: 2005-2021

McCartney MA, Keller G, Lessios HA (2000) Dispersal barriers in tropical oceans and speciation in Atlantic and eastern Pacific sea urchins of the genus Echinometra. Mol Ecol 9:1391-1400
Palumbi SR (1994) Genetic divergence, reproductive isolation, and marine speciation. Ann Rev Ecol Syst 25: 547-572

Posada D, Crandall KA (1998) MODELTEST: testing the model of DNA substitution. Bioinformatics 14: 817-818

Rocha LA, Bowen BA (2008) Speciation in coral-reef fishes. J Fish Biol 72: 1101-1121

Sajdak SL, Phillips RB (1997) Phylogenetic relationships among Coregonus species inferred from the DNA sequence of the first internal transcribed spacer (ITS1) of ribosomal DNA. Can J Fish Aquat Sci 54: 1494-1503

Sakai T (1978) Decapod crustacea from the Emperor Seamount Chain. Researches on Crustacea (Suppl) 8: 1-40

Somerton DA, Donaldson W (1996) Contribution to the biology of the grooved and triangle Tanner crabs, Chionoecetes tanneri and $C$. angulatus, in the eastern Bering Sea. Fish Bull 94: 348357

Takahashi K (1998) The Bering and Okhotsk Seas: modern and past paleocenaographic changes and gateway impact. J Asian Earth Sci 16: 49-58

Tamura K, Nei M (1993) Estimation of the number of nucleotide substitutions in the control region of mitochondrial DNA in humans and chimpanzees. Mol Biol Evol 10: 512-526

Tamura K, Dudley J, Nei M, Kumar S (2007) MEGA4: Molecular Evolutionary Genetics Analysis (MEGA) software version 4.0. Mol Biol Evol 24: 1596-1599

Tang B, Zhou K, Song D, Yang G, Dai A (2003) Molecular systematics of the Asian mitten crabs, genus Eriocheir (Crustacea: Brachyura). Mol Phylogenet Evol 29: 309-316

Thompson JD, Gibson TJ, Plewniak F, Jeanmougin F, Higgins DG (1997) The Clustal $X$ windows interface: flexible strategies for multiple sequence alignment aided by quality analysis tools. Nucleic Acids Res 25: 4876-4882

Yanagimoto T (2007a) Species identification of crabs with molecular markers. In "DNA swimming in the water" Ed by T Saruwatari, Tokai University Press, Kanagawa, Japan, pp 53-76 (in Japanese)

Yanagimoto T (2007b) Identification of three Atelecyclid crab species (Deacapoda: Crustacea) by SSP-PCR analysis. Nippon Suisan Gakkaishi 73: 872-879 (in Japanese with English abstract)

Yosho I, Hayashi I (1994) The bathymetric distribution of Chionoecetes opilio and C. japonicus (Majidae: Brachyura) in the western and northern areas of the sea of Japan. Bull Japan Sea Natl Fish Res Inst 44: 59-71

(Received April 20, 2010 / Accepted September 27, 2010) 